\title{
Well defined carbazol-3,9-diyl based oligomers with diphenylamino end-cap as novel amorphous molecular materials for optoelectronics
}

\author{
Saulius Grigalevicius ${ }^{\mathrm{a}}$, Ming-Han Tsai ${ }^{\mathrm{b}}$, Juozas V. Grazulevicius ${ }^{\mathrm{a}}{ }^{*}$, Chung-Chih Wu ${ }^{\mathrm{b}}$ \\ ${ }^{a}$ Department of Organic Technology, Kaunas University of Technology, Radvilenu Plentas 19, LT 50254 Kaunas, Lithuania \\ ${ }^{\mathrm{b}}$ Department of Electrical Engineering, Graduate Institute of Electro-Optical Engineering and Graduate Institute of Electronics Engineering, \\ National Taiwan University, Taipei 106, Taiwan
}

Received 5 November 2004; accepted 23 February 2005

Available online 9 June 2005

\begin{abstract}
Well defined carbazol-3,9-diyl-based oligomers of new type have been synthesized by the modified Ullmann reaction starting from 3-iodo$9 \mathrm{H}$-carbazole and diphenylamine. The full characterization of their structure is presented. The amorphous compounds with glass transition temperatures of $111-162^{\circ} \mathrm{C}$ possess high thermal stability with onset decomposition temperatures of $320-380^{\circ} \mathrm{C}$. Amorphous films of the materials were fabricated by vacuum evaporation. They were used for the preparation of multilayer electroluminescent devices.
\end{abstract}

(C) 2005 Elsevier B.V. All rights reserved.

Keywords: Amorphous material; Oligomer; Light emitting diode; $\pi$-Electron system

\section{Introduction}

Low molecular weight organic compounds that readily form stable glasses are called molecular glasses or amorphous molecular materials. They show excellent processability, transparency, isotropic and homogeneous properties and receive growing attention both in terms of academic interest and technological applications. Aromatic amine-based molecular glasses belong to the classes of light emitting and charge-transporting materials and are known for various applications such as displays, photovoltaic cells, photorefractive materials and organic photoreceptors [1-3].

The main advantages of electroactive molecular glasses against their polymeric counterparts are their low melt viscosity, possibility of purification by common methods of preparative organic chemistry and a large variety of the methods of synthesis. Molecular glasses can also be obtained by separation of the mixtures of oligomer homologues. In this presentation we report on the preparation of well defined

\footnotetext{
* Corresponding author. Tel.: +370 37456 525; fax: +370 37456525 E-mail address: Juozas.Grazulevicius@ktu.It (J.V. Grazulevicius).
}

carbazol-3,9-diyl based oligomer homologues by Ullmann condensation of 3-iodo-9H-carbazole in the presence of the excess of diphenylamine and the following separation by adsorption chromatography. Variation of the chain length and the end-cap enabled us to obtain a set of amorphous film forming oligomer homologues with relative wide range of glass transition temperatures $\left(T_{\mathrm{g}}\right)$.

\section{Experimental}

\subsection{Instrumentation}

Fourier transform infrared (FTIR) spectra were measured using a Bio-Rad Digilab FTS-40 spectrometer. ${ }^{1} \mathrm{H}$ NMR spectra were recorded using a Bruker DPX 250 apparatus. Mass spectra were obtained on a Varian MAT-312Spectrometer Waters ZQ 200 spectrochromatograph.

Thin films of organic compounds for optical characterization were prepared by vacuum deposition in a high vacuum chamber with a base pressure of $<10^{-6}$ Torr.

Ultraviolet (UV) spectra were measured with a Shimadzu UV-1601PC spectrophotometer. 
Fluorescence (FL) spectra were recorded with a chargecoupled-device (CCD) Aminco-Bowman Series 2 spectrograph by pumping samples with a monochromatic light taken from a xenon arc lamp. Fluorescence quantum yields of thin films were determined using a calibrated integrating sphere system [4].

Differential scanning calorimetry (DSC) measurements were carried out using a TA Instrument DSC-2920 lowtemperature difference scanning calorimeter.

Thermogravimetric analysis (TGA) was performed on a TA Instrument 2950 TGA thermal analyzer. The TGA and DSC measurements were recorded in a nitrogen atmosphere at a heating rate of $10^{\circ} \mathrm{C} / \mathrm{min}$.

The electroluminescence (EL) devices were fabricated on glass substrates and have the typical structure of multiple organic layers sandwiched between the bottom ITO anode and the top metal cathode. Before use in device fabrication, the ITO-coated glass substrates were carefully cleaned and treated with UV-ozone right before organic deposition [5]. The stack of organic layers on ITO in sequence consists of a thin layer of conducting polymer polyethylene dioxythiophene/polystyrene sulphonate (PEDT:PSS) and other functional layers of low molecular weight. The PEDT:PSS layer served as the hole-injection layer and was deposited by spin coating [6]. All the other material layers in devices, including the metal cathode, were deposited by thermal evaporation in a multiple-source vacuum chamber with a base pressure of $<10^{-6}$ Torr. The deposition rate of organic layers was kept at about $0.2 \mathrm{~nm} / \mathrm{s}$. The active area of the device was $1 \mathrm{~mm} \times 1 \mathrm{~mm}$, as defined by the shadow mask for cathode deposition. Thickness of the films was measured by ellipsometry.

The current-voltage-brightness $(I-V-L)$ characteristics of EL devices were measured using a Keithley sourcemeasurement unit and a $\mathrm{Si}$ photodiode calibrated with Photo-Research PR-650 spectroradiometer. The EL spectra of OLEDs were taken with a calibrated CCD SLM-Aminco AB2 spectrograph.

\subsection{Materials}

PEDT:PSS was received from Bayer Corp., 4,4',4"-tri ( $N$-carbazolyl)triphenylamine (TCTA), 4,4'-dicarbazolyl$1,1^{\prime}$-biphenyl (CBP) and 2,2',2'-(1,3,5-benzenetriyl)tris[1-phenyl-1H-benzimidazole] (TPBI) were received from SynTec Gmbh. They were used in this study for preparation of multilayer electroluminescent devices.

Diphenylamine (2), copper powder, 4-iodoanizole, potassium carbonate, 18-crown-6 and 1,2-dichlorobenzene were purchased from Aldrich and used as received. 3-Iodo9H-carbazole (1) was obtained by a procedure of Tucker [7]. 3-Iodo-9-ethylcarbazole was prepared by alkylation of 3-iodo-9H-carbazole in the presence of a phase transfer catalyst [8].

Diphenylamino end-capped oligo(carbazol-3,9-diyl)s with secondary amine functions (3-5) were prepared by the following procedure. An amount of $16.9 \mathrm{~g}(0.1 \mathrm{~mol})$ of diphenylamine (2), $2.25 \mathrm{~g}(35.4 \mathrm{mmol})$ of copper powder, $9.7 \mathrm{~g}(70.11 \mathrm{mmol})$ of potassium carbonate and $0.45 \mathrm{~g}$ (1.65 mmol) of 18-crown-6 in $30 \mathrm{ml}$ of 1,2-dichlorobenzene were heated to $170^{\circ} \mathrm{C}$. An amount of $2.93 \mathrm{~g}(10 \mathrm{mmol})$ of 3-iodo-9H-carbazole (1) in $10 \mathrm{ml}$ of 1,2-dichlorobenzene was added slowly and the mixture was refluxed for $5 \mathrm{~h}$. The inorganic components were then removed by filtration of the hot reaction mixture. The solvent and the excess of diphenylamine were distilled under reduced pressure and the crude mixture of oligomers was precipitated into hexane, filtered and used for the next step reaction.

Ethyl-substituted oligo(carbazol-3,9-diyl)s with diphenylamino end-capp (6 and 7) were prepared by the following procedure. An amount of $2.35 \mathrm{~g}$ (ca. $5 \mathrm{mmol}$ ) of the mixture of oligomers $(3-5), 3.7 \mathrm{~g}(11.5 \mathrm{mmol})$ of 3 iodo-9-ethylcarbazole, copper powder $(1.13 \mathrm{~g}, 17.83 \mathrm{mmol})$, 18-crown-6 $(0.23 \mathrm{~g}, 0.89 \mathrm{mmol})$ and potassium carbonate $(4.24 \mathrm{~g}, 30.76 \mathrm{mmol})$ were dissolved in $o$-dichlorobenzene $(20 \mathrm{ml})$. The solution was stirred at $180^{\circ} \mathrm{C}$ for $24 \mathrm{~h}$. Copper powder and inorganic components were then removed by filtration of the hot reaction mixture. The oligomers were precipitated into $200 \mathrm{ml}$ of methyl alcohol and separated to individual compounds $\mathbf{6}, 7$ and higher molecular weight fraction by silica gel column chromatography using hexane/ethylacetate (vol. ratio 45:1) as an eluent. The yield of compounds $\mathbf{6}$ and $\mathbf{7}$ after separation was 28\%.

Ethyl-substituted di(carbazol-3,9-diyl) with diphenylamino end-capp (6). Elemental analysis for $\mathrm{C}_{38} \mathrm{H}_{29} \mathrm{~N}_{3}$ : \% calc. $\mathrm{N} 7.96, \mathrm{C} 86.50, \mathrm{H} 5.54 ; \%$ found $\mathrm{N} 7.82, \mathrm{C}$ 86.63, H 5.67. IR (KBr), v/cm ${ }^{-1}: 3053,2973(\mathrm{C}-\mathrm{H}, \mathrm{Ar})$, 1588, $1494(\mathrm{CH}=\mathrm{CH}, \mathrm{Ar}), 1274(\mathrm{C}-\mathrm{N}), 1230,1066,747$ $(\mathrm{CH}=\mathrm{CH}, \mathrm{Ar}) .{ }^{1} \mathrm{H}$ NMR $\left(\mathrm{CDCl}_{3}\right), \delta(\mathrm{ppm}): 1.48(\mathrm{t}, 3 \mathrm{H}$, $\left.J=7.2 \mathrm{~Hz},-\mathrm{CH}_{3}\right), 4.38\left(\mathrm{q}, 2 \mathrm{H}, J=7.2 \mathrm{~Hz},-\mathrm{N}-\mathrm{CH}_{2}-\right.$ ), 6.85-8.61 (m, 24H, Ar). MS, $m / z(\%): 529(36)\left[M^{+}+1\right]$, $528(100)\left[M^{+}\right], 337(96)\left[M^{+}-\mathrm{C}_{2} \mathrm{H}_{5}-\mathrm{C}_{12} \mathrm{H}_{8} \mathrm{~N}\right], 260$ (84) $\left[M^{+}-\mathrm{C}_{2} \mathrm{H}_{5}-\mathrm{C}_{12} \mathrm{H}_{8} \mathrm{~N}-\mathrm{C}_{6} \mathrm{H}_{5}\right]$.

Ethyl-substituted ter(carbazol-3,9-diyl) with diphenylamino end-capp (7). Elemental analysis for $\mathrm{C}_{50} \mathrm{H}_{36} \mathrm{~N}_{4}$ : \% calc. N 8.09, C 86.68, H 5.24; \% found N 8.22, C 86.53, H 5.32. IR (KBr), $v / \mathrm{cm}^{-1}: 3053,2974(\mathrm{C}-\mathrm{H}, \mathrm{Ar}), 1588,1493$ $(\mathrm{CH}=\mathrm{CH}, \mathrm{Ar}), 1274(\mathrm{C}-\mathrm{N}), 1229,1067,747(\mathrm{CH}=\mathrm{CH}, \mathrm{Ar})$. ${ }^{1} \mathrm{H} \mathrm{NMR}\left(\mathrm{CDCl}_{3}\right), \delta(\mathrm{ppm}): 1.49\left(\mathrm{t}, 3 \mathrm{H}, J=7.25 \mathrm{~Hz},-\mathrm{CH}_{3}\right)$, 4.39 (q, $2 \mathrm{H}, J=7.2 \mathrm{~Hz},-\mathrm{N}-\mathrm{CH}_{2}-$ ), 6.86-8.55 (m, 31H, Ar). MS, $m / z$ (\%): $694(26)\left[M^{+}+1\right], 693(47)\left[M^{+}\right], 502(100)$ $\left[M^{+}-\mathrm{C}_{2} \mathrm{H}_{5}-\mathrm{C}_{12} \mathrm{H}_{8} \mathrm{~N}\right], 361(22)\left[M^{+}-\mathrm{C}_{12} \mathrm{H}_{8} \mathrm{~N}-\mathrm{C}_{12} \mathrm{H}_{10} \mathrm{~N}\right]$.

Methoxyphenyl-substituted oligo(carbazol-3,9-diyl)s with diphenylamino end-capp (8 and 9) were prepared by the following procedure. An amount of $2.35 \mathrm{~g}$ (ca. $5 \mathrm{mmol}$ ) of the mixture of oligomers $(3-5), 2.5 \mathrm{~g}(11 \mathrm{mmol})$ of 4-iodoanizole, copper powder $(1.13 \mathrm{~g}, 17.83 \mathrm{mmol})$, 18-crown-6 $(0.23 \mathrm{~g}, 0.89 \mathrm{mmol})$ and potassium carbonate $(4.24 \mathrm{~g}, 30.76 \mathrm{mmol})$ were dissolved in $o$-dichlorobenzene ( $20 \mathrm{ml}$ ). The solution was stirred at $180^{\circ} \mathrm{C}$ for $24 \mathrm{~h}$. Copper powder and inorganic components were then removed by 
filtration of the hot reaction mixture. The oligomers were precipitated into $200 \mathrm{ml}$ of methyl alcohol and separated to individual compounds 8,9 and higher molecular weight fraction by silica gel column chromatography using hexane/ethylacetate (vol. ratio 50:1) as an eluent. The yield of compounds 8 and $\mathbf{9}$ after separation was $34 \%$.

Methoxyphenyl-substituted di(carbazol-3,9-diyl) with diphenylamino end-capp (8). Elemental analysis for $\mathrm{C}_{43} \mathrm{H}_{31} \mathrm{~N}_{3} \mathrm{O}: \%$ calc. $\mathrm{N}$ 6.94, C 85.26, H 5.16; \% found $\mathrm{N}$ 6.82, C 85.13, H 5.22. IR (KBr), v/cm $\mathrm{cm}^{-1}: 3073,2969(\mathrm{C}-\mathrm{H}$, $\mathrm{Ar}), 2834\left(\mathrm{OCH}_{3}\right), 1588,1493(\mathrm{CH}=\mathrm{CH}, \mathrm{Ar}), 1274(\mathrm{C}-\mathrm{N})$, 1229, 1067, 998, 789, $747(\mathrm{CH}=\mathrm{CH}, \mathrm{Ar}) .{ }^{1} \mathrm{H} \mathrm{NMR}\left(\mathrm{CDCl}_{3}\right)$, $\delta(\mathrm{ppm}): 3.87\left(\mathrm{~s}, 3 \mathrm{H},-\mathrm{OCH}_{3}\right), 6.72-8.95(\mathrm{~m}, 28 \mathrm{H}, \mathrm{Ar}) . \mathrm{MS}$, $m / z(\%): 606(100)\left[M^{+}+1\right], 504(74)\left[M^{+}-\mathrm{C}_{6} \mathrm{H}_{4}\left(\mathrm{OCH}_{3}\right)\right]$, $421(82)\left[M^{+}-\mathrm{C}_{6} \mathrm{H}_{4}\left(\mathrm{OCH}_{3}\right)-2 \mathrm{C}_{6} \mathrm{H}_{5}\right]$.

Methoxyphenyl-substituted ter(carbazol-3,9-diyl) with diphenylamino end-capp (9). Elemental analysis for $\mathrm{C}_{55} \mathrm{H}_{38} \mathrm{~N}_{4} \mathrm{O}$ : \% calc. N 7.27, C 85.69, $\mathrm{H} 4.97$; \% found $\mathrm{N} 7.42, \mathrm{C} 85.83, \mathrm{H}$ 4.82. IR (KBr), $v / \mathrm{cm}^{-1}$ : 3075, $2970(\mathrm{C}-\mathrm{H}, \mathrm{Ar}), 2834\left(\mathrm{OCH}_{3}\right), 1588,1494(\mathrm{CH}=\mathrm{CH}$, Ar), $1274(\mathrm{C}-\mathrm{N}), 1229,1067,998,789,746(\mathrm{CH}=\mathrm{CH}$, Ar). ${ }^{1} \mathrm{H}$ NMR $\left(\mathrm{CDCl}_{3}\right), \delta(\mathrm{ppm}): 3.88\left(\mathrm{~s}, 3 \mathrm{H},-\mathrm{OCH}_{3}\right)$, 6.76-8.97 (m, 35H, Ar). MS, m/z (\%): 772 (100) $\left[M^{+}+1\right], 586$ (44) $\left[M^{+}-\mathrm{C}_{6} \mathrm{H}_{4}\left(\mathrm{OCH}_{3}\right)-\mathrm{C}_{6} \mathrm{H}_{5}\right], 496$ (23) $\left[M^{+}-\mathrm{C}_{6} \mathrm{H}_{5}\left(\mathrm{OCH}_{3}\right)-\mathrm{N}\left(\mathrm{C}_{6} \mathrm{H}_{5}\right)_{2}\right]$.

\section{Results and discussion}

The synthetic route to well defined carbazol-3,9-diylbased oligomers (6-9) is shown in Scheme 1. Diphenylamino end-capped oligomers with secondary amine functions (3-5) were prepared by the modified Ullmann coupling reaction of 3-iodo-9H-carbazole (1) with a large excess of diphenylamine (2). The large excess of the amine was used in order to prevent polycondensation of 3-iodo-9H-carbazole. When the reaction was over, the excess of diphenylamine was removed and the crude mixture of oligomer homologues (3-5) was treated with an excess of iodocompound, i.e. 3 -iodo-9-ethylcarbazole or $p$-iodoanisole by the Ullmann method, to provide ethyl- or methoxyphenyl-substituted oligo(carbazol-3,9-diyl)s with diphenylamino end-capp. The mixture of oligomer homologues was separated to individual compounds 6-9 by adsorption chromatography and further purified by vacuum sublimation. All the compounds 6-9 were identified by mass spectrometry, IR and electronic absorption, as well as ${ }^{1} \mathrm{H}$ NMR spectroscopy and elemental analysis. The transparent amorphous films of these materials could be prepared by vacuum deposition or spin coating from solutions.

Thermal properties of the materials 6-9 were examined using DSC and TGA analysis under a nitrogen atmosphere.

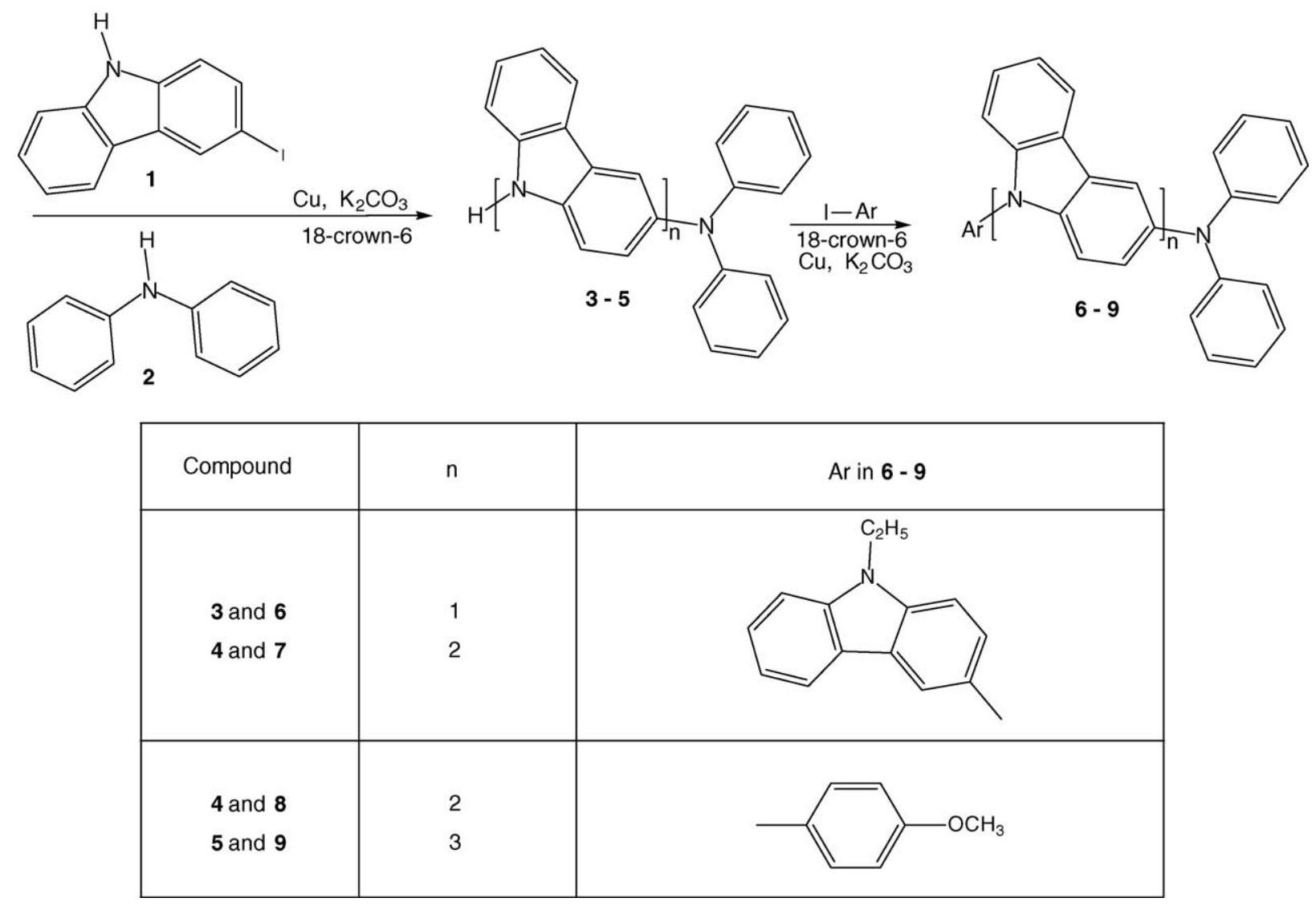

Scheme 1. 
Table 1

TGA data of oligomers $6-9$

\begin{tabular}{lll}
\hline Compound & $T_{\mathrm{ID}}\left({ }^{\circ} \mathrm{C}\right)$ & $T_{5 \%}\left({ }^{\circ} \mathrm{C}\right)$ \\
\hline $\mathbf{6}$ & 326 & 354 \\
$\mathbf{7}$ & 372 & 421 \\
$\mathbf{8}$ & 360 & 389 \\
$\mathbf{9}$ & 383 & 450 \\
\hline
\end{tabular}

TGA measurements revealed that the oligomers synthesized exhibit high thermal stability (Table 1 ). The onset of decomposition for the materials occurred above $320-380^{\circ} \mathrm{C}$. Especially high thermal stability was observed for oligomer 9 which has the highest molecular weight. The temperature of initial decomposition $\left(T_{\mathrm{ID}}\right)$ for 9 was $383^{\circ} \mathrm{C}$, and $5 \%$ weight loss temperature $\left(T_{5} \%\right)$ was observed at $450{ }^{\circ} \mathrm{C}$. It is evident that the thermal stability of the compounds synthesized increases with the increase of their molecular weight (cf. $T_{\mathrm{ID}}$ of $\mathbf{6}$ with that of $\mathbf{7}$, and $\mathbf{8}$ with that of $\mathbf{9}$ ). $T_{\mathrm{ID}}$ depends also on the end group of the oligomers. Compounds with 4methoxyphenyl-end group exhibited higher thermal stability than those with ethyl-end group (cf. $T_{\mathrm{ID}}$ of $\mathbf{6}$ with that of $\mathbf{8}$, and $T_{\mathrm{ID}} \mathbf{7}$ with that of $\mathbf{9}$ ).

All the oligomers were obtained as amorphous glasses as confirmed by DSC (Fig. 1). When samples of the oligomers were heated the glass-transitions were observed at $111^{\circ} \mathrm{C}$ for $6,154{ }^{\circ} \mathrm{C}$ for $7,123^{\circ} \mathrm{C}$ for 8 and at $162^{\circ} \mathrm{C}$ for $\mathbf{9}$, and no peaks due to crystallization and melting appeared. Cooling down and the following repeated heating revealed only the glass transitions again. All the attempts to crystallize the compounds in different solvents failed.

Comparison of the values of $T_{\mathrm{g}}$ shows that increase of the degree of oligomerization by one unit in the series of oligomer homologues leads to the increase of $T_{\mathrm{g}}$ by ca. $40^{\circ} \mathrm{C}$. For example, $T_{\mathrm{g}}$ of dimer $\mathbf{6}$ is by $43^{\circ} \mathrm{C}$ lower than that of trimer 7, and $T_{\mathrm{g}}$ of 8 is by $39^{\circ} \mathrm{C}$ lower than that of compound $\mathbf{9}$. It is also evident that the values of $T_{\mathrm{g}}$ of the compounds can be varied by changing end group of the oligomers. Compounds with 4-methoxyphenyl-end group demonstrate higher $T_{\mathrm{g}}$ than

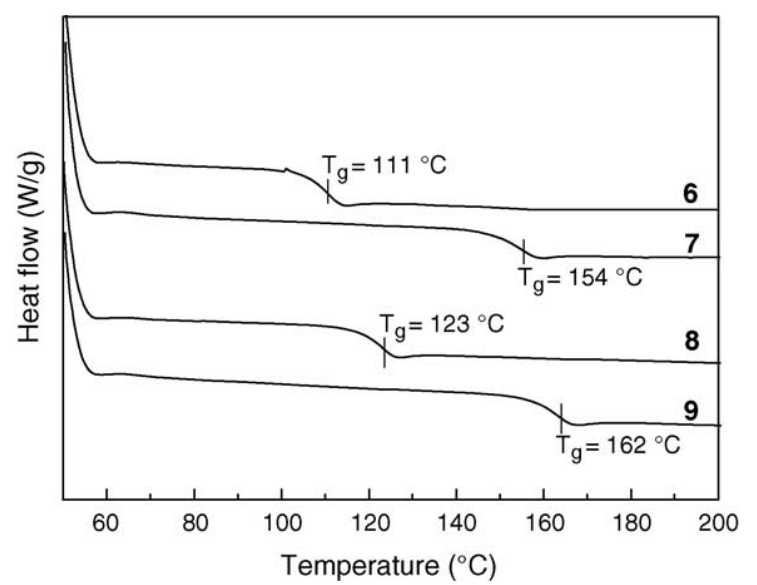

Fig. 1. DSC curves of the oligomers $6-9$ at a heating rate of $10^{\circ} \mathrm{C} / \mathrm{min}$.

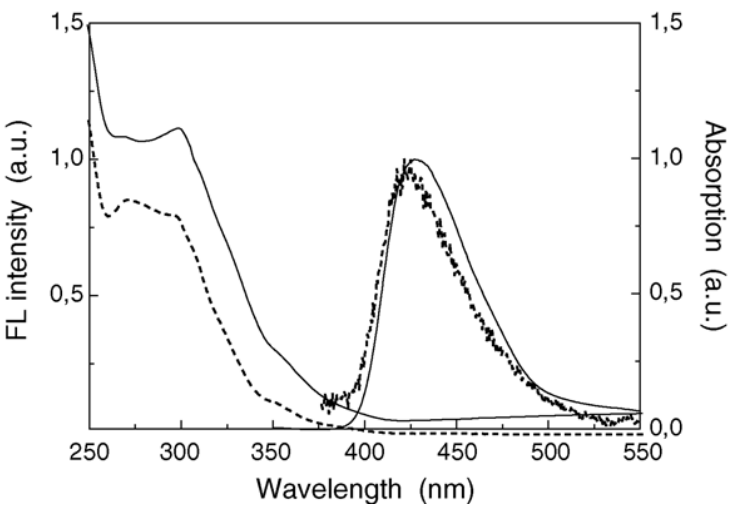

Fig. 2. UV absorption and FL emission spectra of dilute chloroform solutions (dotted line) and of thin films (solid line) of compound 7. $\lambda_{\mathrm{ex}}=325 \mathrm{~nm}$.

those with ethyl-end group (cf. $T_{\mathrm{g}}$ of $\mathbf{6}$ with that of $\mathbf{8}$, and $T_{\mathrm{g}}$ 7 with that of 9 ).

The electronic absorption and fluorescence spectra of dilute chloroform solutions and thin films of compounds 6-9 were recorded. As an example, the spectra of oligomer $\mathbf{7}$ are shown in Fig. 2 and the pertinent data are presented in Table 2.

The electronic absorption energy of these compounds is similar, and the $\lambda_{\max }$ values are in the range of $296-299 \mathrm{~nm}$. Their FL emission maxima appear in the region of wavelengths from 419 to $428 \mathrm{~nm}$. The spectra indicate that an additional carbazol-3,9-diyl group or different end groups in the compounds make no considerable effect on the electronic absorption of the synthesized oligomers.

FL emission spectra of the oligomer films are very similar to the spectra of dilute solutions. This observation shows that there is no influence of molecular interaction on the excited state of the molecules in the solid state. This is understandable as the bulky molecular structure of the carbazol-3,9-diylbased oligomers can efficiently prevent the close stacking of molecules, and thus reduce the extent of molecule interaction in the solid state. The FL quantum yield $\left(\Phi_{\mathrm{FL}}\right)$ reaches 0.21 for the film of oligomer 7 , but it decreases to $0.15-0.16$ for thin films of the other compounds.

Compound 9 with the highest molecular weight and the highest $T_{\mathrm{g}}$ was subjected to the optoelectronic studies. Indium tin oxide (ITO) coated glass was used as the substrate for organic light emitting devices. The stack of organic layers on ITO consisted of a thin layer of conducting polymer PEDT, which was deposited by spin coating and

Table 2

$\mathrm{UV}$ absorption and $\mathrm{PL}^{\mathrm{a}}$ emission maxima, and PL quantum yields ( $\left.\Phi_{\mathrm{FL}}\right)$ of compounds 6-9

\begin{tabular}{lllllll}
\hline Compound & \multicolumn{2}{l}{ UV: $\lambda_{\max }(\mathrm{nm})$} & & \multicolumn{2}{l}{ FL: $\lambda_{\max }(\mathrm{nm})$} & \multirow{2}{*}{$\Phi_{\mathrm{FL}}$} \\
\cline { 2 - 3 } & In solution & In film & & In solution & In film & In film \\
\hline $\mathbf{6}$ & 298 & 299 & & 420 & 423 & 0.16 \\
$\mathbf{7}$ & 296 & 298 & & 425 & 428 & 0.21 \\
$\mathbf{8}$ & 297 & 298 & & 426 & 422 & 0.15 \\
$\mathbf{9}$ & 297 & 298 & & 424 & 425 & 0.16 \\
\hline \multicolumn{2}{c}{${ }^{a} \lambda_{\mathrm{ex}}=325 \mathrm{~nm}}$. & & & &
\end{tabular}




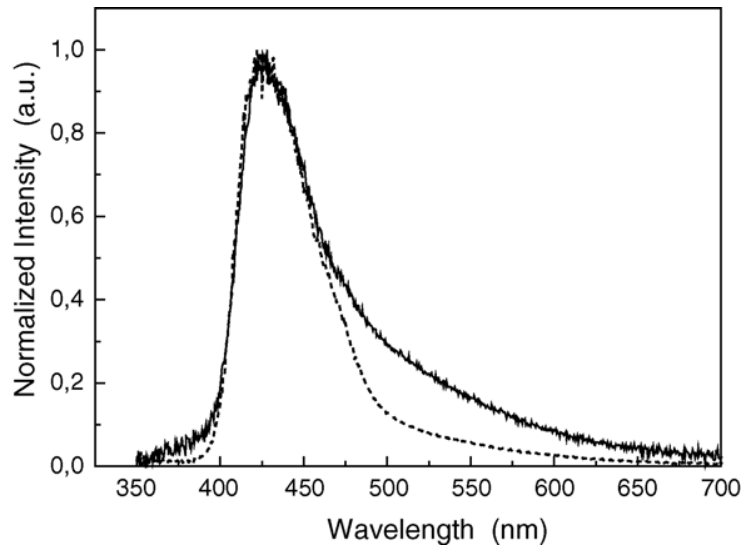

Fig. 3. Comparison of FL spectrum of oligomer 9 (dotted line) and EL spectrum of its electroluminescent device (solid line).

served as hole injection layer, and other functional low molecular weight materials, which were deposited by thermal evaporation. Earlier described materials TCTA [9] and CBP [10] were used as hole transport layers in the devices and TPBI was used as an electron transport layer $[11,12]$. The cathode used consisted of a thin $\mathrm{LiF}$ electron injection layer and a thick $\mathrm{Al}$ layer as a metal electrode. When a device ITO/PEDT/TCTA $(40 \mathrm{~nm}) /$ compound 9 $(30 \mathrm{~nm}) / \mathrm{TPBI}(30 \mathrm{~nm}) / \mathrm{LiF} / \mathrm{Al}$ was fabricated, a blue EL with a maximum around $425 \mathrm{~nm}$ was obtained. This emission maximum overlapped with the FL emission of a pure 9 film itself (Fig. 3). This implies that the charge recombination occurs in the layer of oligomer 9. The small difference between the spectra here implies that the recombination mechanisms of some charge carriers for FL and EL are different and some EL from excimer emission of the oligomer 9 is, apparently, observed. A similar phenomenon was reported for binaphthalene and triarylamine based polymers [13,14].

Low EL quantum efficiency suggested poor balance of hole and electron currents and/or poor confinement of carriers and excitons in the device. More advanced heterostructure device: ITO/PEDT/TCTA $(20 \mathrm{~nm}) / \mathrm{CBP}(20 \mathrm{~nm}) /$ compound 9(30 nm)/TPBI $(30 \mathrm{~nm}) / \mathrm{LiF} / \mathrm{Al}$ employing CBP as an additional hole-transporting layer in combination with TCTA was then investigated. It was observed that under the present configuration the charge recombination occurred also in the layer of oligomer 9 . The inserting of the second hole transporting layer which HOMO energy level is lying between that of TCTA and compound 9 helps the migration of holes and enhances substantially the EL quantum efficiency to $0.4 \%$. Fig. 4 shows current-voltage and luminance-voltage characteristics for the device. The rather low turn-on voltage of $3.5 \mathrm{~V}$, defined as the voltage where EL emission becomes detectable, and relatively low operation voltage $\left(100 \mathrm{~cd} / \mathrm{m}^{2}\right.$ at $\sim 9 \mathrm{~V}$ ) of this device suggested that the carbazol-3,9-diyl based oligomers can function well as hole transporters.

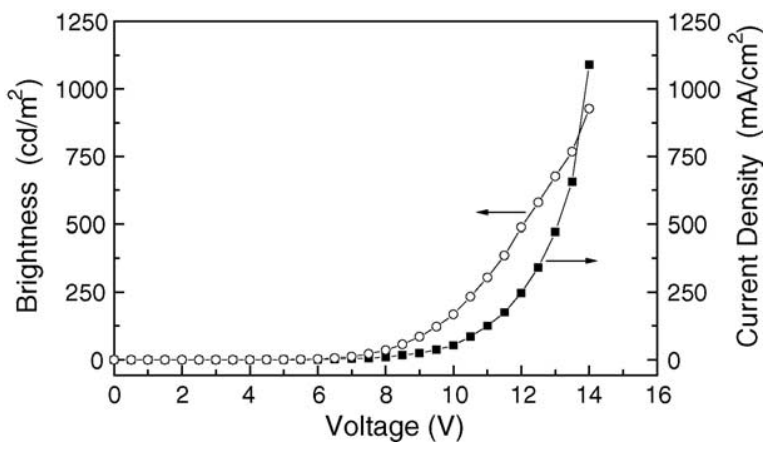

Fig. 4. LED characteristics of multilayer devices: ITO/PEDT/TCTA $(20 \mathrm{~nm}) / \mathrm{CBP}(20 \mathrm{~nm}) /$ oligomer $9(30 \mathrm{~nm}) / \mathrm{TPBI}(30 \mathrm{~nm}) / \mathrm{LiF} / \mathrm{Al}$.

In conclusion, a series of new carbazol-3,9-diyl-based oligomers with high thermal stability and interesting optoelectronic properties have been synthesized using the improved Ullmann reaction. The possibility to use these amorphous materials for blue light emitting devices was demonstrated.

\section{Acknowledgements}

This research was conducted in the frame of the joint research program of Latvia, Lithuania and Taiwan. Financial support from the National Science Council of Taiwan and from the Lithuanian Ministry of Education and Science is gratefully acknowledged.

\section{References}

[1] Y. Shirota, J. Mater. Chem. 10 (2000) 1.

[2] P. Strohriegl, J.V. Grazulevicius, Adv. Mater 14 (2002) 1439.

[3] M. Thelakkat, Macromol. Mater. Eng. 287 (2002) 442.

[4] C.-C. Wu, W.-Y. Hung, T.-L. Liu, L.-Z. Zhang, T.-Y. Luh, J. Appl. Phys. 93 (2003) 5465.

[5] C.W. Tang, S.A. Van Slyke, Appl. Phys. Lett. 51 (1987) 913.

[6] A. Elscher, F. Bruder, H.-W. Heuer, F. Jonas, A. Karbach, S. Kirchmeyer, S. Thurm, R. Wehrmann, Synth. Met. 111 (2000) 139.

[7] S.H. Tucker, J. Chem. Soc. 1 (1926) 548.

[8] J.M. Rodriguez-Parada, K. Persec, Macromolecules 19 (1986) 55.

[9] Y. Kuwabara, H. Ogawa, H. Inada, N. Noma, Y. Shirota, Adv. Mater. 6 (1994) 677.

[10] Y.T. Tao, E. Balasubramaniam, A. Danel, P. Tomasik, Appl. Phys. Lett. 77 (2000) 933.

[11] L.S. Hung, C.W. Tang, M.G. Mason, Appl. Phys. Lett. 70 (1997) 152.

[12] Y. Li, M.K. Fung, Z. Xie, S.-T. Lee, L.-S. Hung, J. Shi, Adv. Mater. 14 (2002) 1317.

[13] T. Isoshima, T. Wada, Y.-D. Zhang, E. Brouyere, J.-L. Bredas, H. Sasabe, J. Chem. Phys. 104 (1996) 2467.

[14] W.-L. Yu, J. Pei, W. Huang, A.J. Heeger, Chem. Commun. 8 (2000) 681. 